\title{
CONSTELAÇÃO FAMILIAR E ESQUIZOFRENIA
}

\author{
ANTONIOS I. TERZIS *
}

A psicologia do grupo familiar é um movimento psicológico, uma inovação terapêutica e o esboço de teorja própria da patogênese familiar que inclui em seu dominio diversos ramos como: psicanálise, cibernetica, teoria geral dos sistemas, sociologia, antropologia e várias teorias sobre formação da personalidade. Apesar da fragmentaçāo evidente das diversas aproximaçōes teóricas, duas correntes parecem haver favorecido o desenvolvimento da psicologia do grupo familiar: a primeira, através da evolıção do pensamento psicanalítico; a segunda, através do desenvolvimento da sociologia e da antropologia. Os estudos psicanaliticos sobre a familia foram precedentes aos trabalhos sociologicos. Estes abriram novo horizonte năo somente às técnicas terapêuticas mas, também, à de maneira mais aprofundada de compreender as hipóteses sobre o desenvolvimento mental do homen e 0 papel da família em relação a determinadas doenças mentais.

O papel da familia foi percebido principalmente nos anos de 1940 a 1950 , devido à frequiência de traços patológicos nos pais de pacientes mentais. Nesse sentido, estudos realizados sobre pacientes mentais e seus familiares parecian procurar caminhos coerentes em relação à etiologia de determinada entidade psicopatológica. A maioria desses trabalhos procurava descrever o funcionamento intrafamiliar e os fatores específicos que, dentro do ambiente, dificultam o desenvolvimerito mental da pessoa 12. Em geral, o funcionamento intrafamiliar é descrito mediante dois modelos diferentes dos quais cabe dar diretrizes gerais. Um deles é o modelo transgeracional que descreve as relaçōes dinâmicas das gerações anteriores do paciente. Por exemplo, sustenta-se que a esquizofrenia é processo que requer três ou mais gerações para se desenvolver 3 . O material clínico correspondente ao conceito transgeracional chama a atenção acerca do fracasso comum dessas familias para manter os limites essenciais entre as gerações sucessivas. O segundo modelo de funcionamento intrafamiliar é o transacional, que descreve as relações dinâmicas entre os membros da familia. Estudos ilustram os princípios dinâmicos que regem as relaçōes entre paciente e seu ambiente familiar em especial.

O estudo sobre desvios maritais se orienta em grande parte a dois tipos de familias patogênicas: à família em que domina uma figura central patológica (o pai ou a mãe); à familia em que o pai ou a mãe escolhem para si um filho e se aliam contra o outro cônjuge 7 . Esses pais, modelos imperfeitos para identificação e para o objeto primário de amor para com a criança, constituem modelos estranhos de relacionamentos interpessoais 14 . Da mesma forma, os conceitos pseudo-mutualidade e pseudo-hostilidade explicam como a familia se comporta, como se nada funcionasse mal ou errado frente a problemas mais terríveis. Nesse sentido, o importante è estar sempre de acordo quanto ao que se está de acordo; um desacordo sobre o conteúdo da mensagem indica, nessas familias, a possibilidade de rotura na relação. Porém, as palavras não têm um sentido informativo mas, sim, valor relacional que permite à pessoa continuar a viver no seio de sua familia 16. Nesse tipo de comunicação, a identidade individual é sacrificada pelo mito da identidade coletiva, sentida como um

* Professor Titular do Departamento de Pós-Graduação em Psicologia Clínicu, Pontificia Universidade Católica de Campinas (PUCCAMP). 
bloqueio solidário e não diferenciado, em que 0 filho se comporta e funciona como se ele e a família fossem uma unidade 8.

De fatu, a atenção concentra-se cada vez mais na interaçăo dos pacientes com os membros de suas famílias, com especial concentração à comunicação. A palavra dos pais passou a ser o centro dos principais trabalhos nos Estados Unidos. A escola de Palo Alto (Califórnia) preocupa-se apenas com as comunicações recebidas e emitidas pelo individuo. Portanto, todos os problemas serão colocados em termos de comunicações (teoria dos sistemas) - o nexo patológico na esquizofrenia é explicado pela hipótese do duplo-vínculo. A teoria do duplo-vínculo trata de mensagem que possui uma contradição entre seus dois níveis: o nível mais superficial, informativo, que implica numa proibição, e o nivel mais profundo, não-verbal, da intercomunicação, que inverte essa proibição. Finalmente, o receptor é incapaz de fazer comentários acerca das mensagens que estão sendo transmitidas, porque se encontra aprisionado, numa posição em que não pode ganhar e da qual năo pode sair por se encontrar entre mensagens opostas 2 . O ponto essencial desse termo é o fato das familias se interatuarem de tal forma que colocam o filho em situação difícil - em que atue ou não atue, sempre se equivocará. Portanto, o filho não pode comentar, esclarecer ou questionar as contradições. O filho comporta-se e funciona como se ele e a família fossem um sistema único.

Reagrupando essas teorias - duplo-vínculo, pseudo-mutualidade, desvios maritais, transgeracional - fragmentárias que reunem uma série de observações clinicas, tem-se a impressão de que os diferentes autores têm percebido a mesma gama de fenômenos no grupo familiar do paciente, enquanto cada um deies utiliza linguagem distinta. Notamos nesses estudos que a família do esquizofrênico não proporciona aos filhos modelos de papéis apropriados. Em geral, impedem que $o$ filho alcance identidade própria e liberdade de pensamento. A criança é mantida em uma rede de comunicações sem trocas verdadeiras e sem possibilidade de identificação, com as imagens parentais mal delineadas e indiscerniveis. Ainda, esses achados familiares podem ser associados ao quadro clínico dos pacientes esquizofrênicos: a baixa auto-estima no paciente parece estar relacionada com seu papel históricu como o membro de família débil, dependente 7,8. O fenômeno de baixa auto-estima está relacionado com a pobre identidade e sentido de si mesmo e que resulta da sua própria familia. As perturbações de percepção, pensamento e atenção, reconhecidas como características de muitos pacientes esquizofrênicos, são, de acordo com os relatos, de comunicação confusa e irracional do grupo familiar 16 . A intensa ambivalência notada em muitos pacientes esquizofrênicos pode ser entendida como expressão aberta de ambas as partes, das expectativas contraditórias que têm experimentado com seus familiares 2 .

Finalmente, é importante considerar para a finalidade deste trabalho não somente a dinâmica interacional, mas também certas variáveis familiares objetivas, que são passíveis até de quantificação, como por exemplo: a ordem de nascimento dos filhos 13; o tamanho da família 1 ; 0 sexo do irmão que 0 sucede e a diferença de idade entre eles 10; a idade dos pais quando o filho nasceu; os motivos determinantes da desagregação familiar 11; o nivel sócioeconômico e cultural da família 4. Há outras variáveis relacionadas ao tema, como 0 fato de ser o filho menino ou menina, fato esse que pode afetar profundamente o relacionamento entre os pais. As vezes é um menino que é desejado por ambos; outras vezes o pai deseja uma menina e a mãe um menino ou vice-versa 15. Ainda, são possiveis situações em que irmãos, do mesmo sexo ou de sexo diferente, entram em rivalidade uns com os outros. A apreciaçăo de cada um desses casos torna-se, pois, consideravelmente difícil. Tal é, por exemplo, a situação de uma menina entre vários irmãos ou vice-versa.

Especificamente o que interessa neste trabalho é investigar os tópicos seguintes: qual o nivel sócio-econômico e cultural familiar numa população bra- 
sileira de esquizofrênicos; qual o tamanho da prole desses pacientes; qual o sexo do irmäo que precede o paciente na ordem de nascimento; qual o papel de segurança física e emocional que os familiares transmitiram ao esquizofrênico.

\section{CASUFSTICA E METODOLOGTA}

Foram levantadas informaç̋es sobre 404 pacientes diagnosticados como esquizofrênicos, hospitalizados em 5 hospitais psiquiátricos da área metropolitana de são Paulo: 201 homens e 203 mulheres, na maioria internados pelo sistema previdenciário. A seleção dos pacientes que integram a amostra foi feita após estudo do exame psiquiátrico realizado pela equipe profissional do hospital.

Para a coleta dos dados foram seguidos três passos: (a) consulta ao prontuário do paciente, visando à confirmação do diagnóstico definitivo da esquizofrenia; (b) entrevista clínica dirigida, com o paciente, feita com o objetivo de se obter dados pessoais e familiares; (c) contato com a familia do paciente, através da qual se obtivesse confirmação daqueles dados fornecidos pelo próprio paciente, para garantir maior fidedignidade desses dados. Como grupo de controle, escolhemoz a população geral (IBGE) da qual os pacientes são provenientes (5).

\section{RESULTADOS}

A maioria dos pacientes internados $(85,74 \%)$ provinha de uma familia de balxo nível sócio-econômico e cultural (denominamos baixo nivel sócio-econômico-cultural fatores como: falta de recursos humanos básicos; maioria dos pacientes sem escolaridade; condiçōes habitacionais menos propícias; instabilidade de trabalho e rendas familiares $\mathrm{e}$ individuais baixas). $O$ número médio de filhos por mulher, entre as mães dos pacientes, foi bastante elevado: $6,60 \%$, sendo $6,43 \%$ para as proles às quais pertenciam os pacientes do sexo masculino e $6,76 \%$ para as proles às quais pertenciam os pacientes do sexo feminino, enquanto $o$ valor médio de filhos por mulher na populasaao geral era 4,65\%, conforme o Censo Demográfico de 1980 para o Estado de São Paulo (6). Procurou-se averiguar o sexo do irmão que precede o paciente na ordem de nascimento; essa variável parece raramente investigada; verificamos que o irmåo que o precede é do sexo oposto (em 50,8\% dos casos masculinos e em $63 \%$ dos femininos). A maioria das famílias de pacientes esquizofrênicos era desorganizada (55\%); quanto à fdade dos pacientes, quando se deu a desagregaçăo familiar, verificou-se que a maioria tinha entre zero e três anos de idade (chamamos desagregação familiar os motivos determinantes, como: separação consensual, morte de um dos pais, doença mental, abandono do lar temporariamente, ocupação do pai ou da mãe exercida em outro Estado ou país por muitos anos). A relação com seus pais tem sido insatisfatória em $86,6 \%$ dos pacientes masculinos e $93,3 \%$ dos casos femininos (chamamos relação insatisfatória aquela que por motivos de carências alimentar e afetiva, instabilidade ou traços patológicos, o grupo familiar não tinha condiçōes de satisfazer as necessidades psicossociais básicas).

\section{COMENTARIOS}

Os pacientes esquizofrênicos estudados emergiram de familias marcadas por desagregação e provêm de nível sócio-econômico-cultural baixo. Provavelmente, a situação de pobreza em que vivem e a ignorância sobre o controle de natalidade expliquem a tendência a terem grandes proles (6,60 filhos).

Supomos, pelo conjunto dos dados, que essas famílias não preencheram as necessidades básicas (psicobiológicas) da criança, nem coerentemente transmitiram os meios ou instrumentos culturais para o paciente no período da infância. Entre a extensa literatura concernente à familia, destaca-se a crescente e cons- 
tante evidência de que a natureza dos cuidados proporcionados pelos pais aos filhos, durante sua primeira infância, é de fundamental significação no futuro de sua saúde mental $\mathbf{9 , 1 5}$.

De certa forma, os resultados do presente estudo encontram respaldo nas teorias relacionadas à etiologia da esquizofrenia, que enfatizam a importância do funcionamento intrafamiliar e a caracterologia individual de cada um dos integrantes do grupo familiar 2,3,7,8,14,16. Assim, entende-se que estudos sobre a estrutura do grupo familiar são indispensáveis no campo terapêutico. Especialmente estudos retrospectivos que possam ilustrar como era o meio familiar de um esquizofrênico e as manifestaçöes psicopatológicas de seus integrantes.

\section{RESUMO}

O presente trabalho tem como propósito estudar o grau de associação entre variáveis familiares e a esquizofrenia. Para o objetivo proposto, foram observados 404 pacientes esquizofrênicos (201 do sexo masculino e 203 do sexo feminino), que estavam internados em 5 hospitais psiquiátricos da área metropolitana de São Paulo. A maioria dos pacientes provinha de uma família de baixo nivel sócio-económico-cultural. O número médio de filhos por mulher, entre as mães dos pacientes, foi bastante elevado, 6,60, enquanto esse valor médio era 4,65 na população geral. Havia desagregação familiar em $55 \%$ dos casos estudados. Quanto à idade dos pacientes quando se deu a desagregação familiar, verificou-se que a maioria tinha entre zero e três anos.

\section{SUMMARY}

\section{Family constelation and schizophrenia.}

The purpose of the present study is to investigate the association between certain family characteristics and schizophrenia. In order to examine the proposal, 404 schizophrenic pacients (201 males and 203 females) from 5 psychiatric hospitals situated in the great metropolilan area of São Paulo were observed. The majority of the pacients came from families very poor $(85.74 \%)$. Over half the patients came from families of 4 to 8 siblings, and the average number of children per mother in those families was significantly higher $(6.60)$ in comparison with the average figure for the population in general (4.65). Regarding the family disruption in about $55 \%$ of the cases this factor was present. As to the age of the patients at the family breakup, the majority of the subjects studied ranged from 0 to 3 years of age.

\section{REFERANCIAS}

1. BARRY, H. \& BARRY, H.J. - Birth order, family size and schizophrenia. Arch. gen. Psychiat. 17:435, 1967.

2. BATESON, G.; JACKSON, D.; HALEY, J. \& WEAKLAND, J. - Towards a theory of schizophrenia. Behav. Science 1:251, 1956.

3. BOWEN, M. - Esquizofrenia y familia. In: D. Jackson: Etiologia de la Esquizofrenia. Trad. por F. Setaro. Amorrortu, Buenos Aires, 1960. 
4. BUCHER, R. \& TERZIS, A. - Ordem de nascimento e relacionamento fraterno de pacientes esquizofrênicos. Arq. Neuro-Psiquiat. (São Paulo) 38:53, 1980.

5. IBGE - Sinopse Preliminar do Censo Demográfico: São Paulo. IBGE, Rio de Janeiro, 1981.

6. IBGE - Tabulaçōes Avançadas do Censo Demográfico: Resultados Preliminares. IBGE, Rio de Janeiro, 1981.

7. LIDZ, T.; CORNELISON, A.; CARLSON, D.T. \& FLICK, J. - El Medio Intrafamiliar del Paciente Esquizofrenico en la Transmisión de la Irracionalidade en Interacción Familiar. Tímpo Contemporaneo, Buenos Aires, 1971.

8. MOSHER, L.R. - Implicancias de los estudíos de la familia para el tratamento de la esquizofrenia. Terapia Familiar 1:49, 1978.

9. SPITZ, R.A. - De la naissance à la narole, la premiére année de la vie de l'enfant. P.U.F., Paris, 1968.

10. TERZIS, A. - Ordem de nascimento, tamanho da prole e esquizotrenia. U.S.P., São Paulo, 1983.

11. TERzis, A. - Epidemiologia da esquizofrenta e certas variáveis demográficas. Estudos de Psicologia PUCCAMP 1:33, 1984.

12. TERzIS, A. - Psicologia do grupo familiar e sua relação no processo esquizofrénico. Estudos de Psicologia PUCCAMP 2:73, 1985.

13. Terzis, A. - Posição ordinal dos filhos, sexo e esquizofrenia. Arq. Neuro-Psiquiat. (São Paulo) 44:147, 1986.

14. VASSILIOU, G. - Aspectos de las relaciones entre padres y adolescentes en la familia griego. In T. Lidz - El Adolescente y su Familia. Paidós, Buenos Aires, 1972.

15. WINNICOT'T, D.W. - L'Enfant et sa Famille. Payot, Paris, 1971.

16. WYNNE, L.C.; RYCKOFF, I.M. \& DAY, J. - Pseudo-mutuality in the family relations of schizophrenies. Psychiatry 21:205, 1958.

Wepto. de Pós-Graduaşón em Psicologia Clinica, Pontifícia Universidade Católica de Campinas - Caixa Postal 317 - 13100 - Campinas, SP - Brasil. 